\title{
POTENCIAL PAISAGÍSTICO DE PLANTAS NATIVAS DE SANTO ÂNGELO-RS
}

\section{LANDSCAPE POTENTIAL OF SANTO ANGELO-RS NATIVE PLANTS}

\author{
Ricardo Dreilich Prestes ${ }^{1}$, Vanessa Backes Nascimento Diel ${ }^{1} \&$ Nilvane Teresinha \\ Ghellar $^{2}$
}

${ }^{1}$ Universidade Regional Integrada do Alto Uruguai e das Missões (URI), Santo Ângelo, RS, Brasil; ${ }^{2}$ Setrem Sociedade Educacional de Três de maio, RS, Brasil.

\section{RESUMO}

Introduçáo: o paisagismo é essencial para o equilíbrio ecológico, pois os espaços verdes estão sendo cada vez mais ocupados. Objetivo: assim, o objetivo deste trabalho foi analisar a possibilidade do uso de plantas nativas que ocorrem na cidade de Santo Ângelo - RS, em projetos paisagísticos e de ornamentação. Metodologia: foi realizada através de uma pesquisa quantitativa e posteriormente uma pesquisa bibliográfica das espécies com potencial para paisagismo e ornamentação. Foram selecionadas por acessibilidade urbana as plantas (herbáceas, subarbustos, arbustos e trepadeiras) nativas de ocorrência na cidade de Santo Ângelo para descrever seu potencial paisagístico. Por seguinte, foi elaborada uma tabela com as características paisagísticas de cada espécie vegetal. Resultados: durante as saídas de campo foram registrados por fotografia 73 indivíduos, sendo identificadas, 36 espécies nativas com potencial paisagístico, pertencentes a 13 famílias botânicas: Asteraceae (8), Acanthaceae (1), Commelinaceae (2), Concolvulaceae (3), Iridaceae (3), Lythraceae (2), Malvaceae (1), Onagraceae (1), Oxalidaceae (3), Poaceae (5), Rubiaceae (1), Solanaceae (2) e Verbenaceae (2). Quanto aos hábitos de vida dessas plantas, foram encontrados quatro categorias de classificação: arbusto (3), subarbusto (7), herbáceo (23) e trepadeira (3). A cidade de Santo Ângelo apresentou uma grande diversidade de espécies nativas que podem ser utilizadas no paisagismo e na ornamentação, no entanto, é necessário trabalhar o conhecimento popular acerca desses vegetais com a população urbana.

Descritores: Levantamento. Vegetação. Ornamentação.

\section{ABSTRACT}

Introduction: Landscaping is essential for ecological balance, as green spaces are being increasingly used. Objective: thus, the objective of this work was to analyze the possibility of using native plants that occur in the city of Santo Angelo - RS, in landscape and ornamentation projects. Methodology: was carried out through a quantitative search and later a bibliographic search of the species with potential for landscaping and ornamentation. Plants (herbaceous, sub-shrubs, shrubs and vines) native to the city of Santo Angelo were selected for urban accessibility to describe their landscape potential. Next, a table was drawn up with the landscape characteristics of each plant species. Results: During the field trips 73 individuals were registered by photograph, being identified, 36 native species 
with landscaping potential, belonging to 13 botanical families: Asteraceae (8), Acanthaceae (1), Commelinaceae (2), Concolvulaceae (3), Iridaceae (3), Lythraceae (2), Malvaceae (1), Onagraceae (1), Oxalidaceae (3), Poaceae (5), Rubiaceae (1), Solanaceae (2) and Verbenaceae (2). As for the life habits of these plants, four categories of classification were found: shrub (3), sub-shrub (7), herbaceous (23) and creeper (3). The city of Santo Angelo presented a great diversity of native species that can be used in landscaping and ornamentation, however, it is necessary to work on popular knowledge about these plants with the urban population.

Descriptors: Survey. Vegetation. Ornamentation.

\section{INTRODUÇÁO}

Vivemos em uma era em que as pessoas se distanciam cada vez mais da natureza, principalmente em grandes cidades. Nesse sentido, a flora entra como um recurso muito importante, pois remete beleza cênica, essencialmente as plantas nativas de cada regiáo. Além disso, quando seu uso for planejado, adequadamente nos perímetros urbanos, pode facilitar a melhoria da qualidade ambiental ${ }^{1}$. As coberturas vegetais de centros urbanos exercem diversas melhorias na qualidade do ambiente, purificando o ar pela fixação de poeira, gases tóxicos e também, reciclam gases através de seus mecanismos fotossintéticos, onde a planta absorve e incorpora gás carbônico e outros, gerados por várias atividades humanas, em especial, à queima de combustíveis fósseis. Além disso, os vegetais liberam oxigênio para a atmosfera e auxiliam na manutenção da temperatura e umidade, através de suas folhas evaporam grandes volumes de água ${ }^{2}$.

Com a expansão das cidades e seus processos de intensificaçóes urbanas, o contato entre homem e natureza se tornou menos habitual, então, para se conectar com o mundo natural e diminuir este paradigma, as pessoas buscam mais por atividades de lazer como passeios em campos, florestas, bosques, camping, praias, entre outros. Também cultivam espaços verdes em meio ao concreto dos ambientes construídos e até mesmo, em suas residências, praticando diversos esportes. Dessa maneira, como uma forma racional do contato homem-natureza, veem o paisagismo, com o intuito de planejar espaços verdes e jardins ${ }^{3}$. Para tanto, o fascínio das pessoas em relação aos jardins é a possibilidade de reproduzir a natureza, em espaços privados, encantando e despertando a imaginaçáo, com as várias cores e formas que as plantas podem proporcionar ${ }^{4}$.

O Brasil é mundialmente conhecido por sua rica biodiversidade, os dados da flora, descrevem cerca de 44.830 mil espécies vegetais, para tanto, muitas dessas plantas possuem potencial ornamental de valor comercial praticamente inexplorado, incluindo espécies vegetais que nunca foram utilizadas na ornamentação. O destaque da flora brasileira está no número de plantas produtoras de grandes flores coloridas, cujo efeito ornamental seria extraordinário, se houvesse interesse em cultivá-las em jardins, praças, e outros locais. Plantas ornamentais nativas do Brasil, e também, do Rio Grande do Sul destacam-se pelo 
seu florescimento, formato ou colorido das folhas, bem como aspecto geral da planta, podendo ser de hábitos variados (árvores, arbustos, trepadeiras, herbáceas) ${ }^{5}$.

No Brasil, especialmente na Região Sul, a falta de pesquisas com plantas ornamentais nativas, faz com que a oferta de espécies nativas em viveiros comerciais não seja comum, restringindo assim seu uso em projetos de paisagismo. De tal modo, muitas plantas nativas podem se extinguir, mesmo antes de seu potencial paisagístico ser reconhecido e utilizado, além de que o uso dessas espécies vegetais nativas em projetos paisagísticos pode ser um importante instrumento de conservação ${ }^{6}$. Como no caso de plantas nativas dos Biomas Mata Atlântica e Pampa, que estão sobre alto risco de extinção. Para a Mata Atlântica estima-se que 607 espécies estáo em risco de extinção e no Pampa cerca de 250 espécies. Assim, existe a necessidade de haver pesquisas mais aprofundadas sobre o potencial paisagístico dessas espécies a fim de conservação e aumento dessas populaçốes de plantas ${ }^{7}$.

É de grande importância à utilização de vegetação nativa no paisagismo, relevante para a conservação da diversidade nativa local, especialmente, na substituição de plantas exóticas por nativas, devido a características de adaptação ao meio, regionalismo, diversidade biológica e importante papel ecológico no paisagismo. De tal forma, as plantas nativas podem proporcionar diversos ganhos, devido à menor exigência para a sua manutenção, em função da rusticidade e adaptação. E até mesmo, pela fácil disponibilidade dessas plantas para a comercialização, assim representam um diferencial no mercado; mas também sua produção e comercialização constituem opção para a geração de emprego e renda ${ }^{8}$.

A tendência do urbanismo contemporâneo é de ampliar os valores ambientais, de modo que o paisagismo valorize mais a ecologia urbana e o planejamento do ambiente. No entanto, na história do paisagismo sul-rio-grandense é notória a cópia de modelos estrangeiros. Acompanhando a arquitetura, os jardins do Brasil seguiram o ritmo das influências culturais do exterior, prevalecendo ainda hoje um modelo norte-americano. Dessa forma, como alternativa, a flora do Rio Grande do Sul é diversa e reúne um conjunto de espécies de valor ornamental com alto potencial para o emprego no paisagismo ${ }^{7}$. Assim, o objetivo deste trabalho foi analisar a possibilidade do uso de plantas nativas que ocorrem na cidade de Santo Ângelo - RS, em projetos paisagísticos e de ornamentação como forma de valorizar as plantas locais nativas.

\section{MÉTODO}

O trabalho foi desenvolvido na cidade de Santo Ângelo, a qual faz parte do bioma Mata Atlântica, com as coordenadas $28^{\circ} .29^{\prime} 5852^{\prime \prime}$ de latitude sul e 54 $24^{\circ} 4567^{\prime \prime}$ de latitude oeste, possuindo uma área de $680,498 \mathrm{~km}^{2}$. A cidade de Santo Ângelo é 
considerada a Capital das Missóes com 79.040 habitantes ${ }^{8}$. Esta cidade localiza-se na encosta Ocidental do Planalto Médio Rio-Grandense, Região Noroeste do Estado, Zona Fisiográfica das Missões. A vegetação descrita em maior parte de sua extensão é a de Floresta Estacionais Decidual ${ }^{9}$. A temperatura média anual é de $21,8^{\circ} \mathrm{C}$ e a precipitação anual é de $1734,5 \mathrm{~mm}^{10}$. O tipo de solo é o Latossolo Vermelho Distroférrico Típico ${ }^{11}$. O clima é subtropical úmido, do tipo Cfa, conforme a classificação de Köppen ${ }^{12}$.

O presente estudo foi realizado através de pesquisa quantitativa de famílias e espécies vegetais e posteriormente uma pesquisa bibliográfica dessas espécies vegetais sobre seu potencial paisagístico e/ou ornamental. Foram selecionadas por acessibilidade urbana as plantas nativas de ocorrência no perímetro urbano de Santo Ângelo-RS para descrever seu potencial paisagístico. $\mathrm{Na}$ pesquisa fez-se o uso de artigos, periódicos, dissertações, teses, e-books, livros, livretos, decretos, sites da internet, leis, entre outros documentos.

A seleção das espécies considerou quanto aos hábitos de vida das plantas, quatro categorias de classificação: arbusto, subarbusto, herbáceo e trepadeira. Ainda durante as saídas de campo, as plantas escolhidas foram aquelas de maior destaque, seja pela flor vibrante e vistosa, folhas vistosas e harmônicas e a estética do conjunto de todos esses aspectos para uma possível utilização na ornamentação. Foi elaborada uma tabela com algumas características de cada espécie vegetal (textura, cor, indicativa de uso e potencial ornamental), incluindo a indicação de locais onde podem ser cultivadas.

Para o levantamento das espécies foram realizadas saídas a campo em três períodos diferentes do ano de 2019: março, junho e setembro, englobando plantas com período reprodutivo em diferentes estaçóes, visando assim uma diversidade maior de espécies e utilidades. As caminhadas foram realizadas em diferentes áreas urbanas da cidade de Santo Ângelo, onde se percorreram ruas, avenidas e travessas (Av. Apolinário Dornelles de Moraes, R. Cerro Largo, Tv. das Carmelitas, Av. Jorge Menezes, Tv. Begônias, Tv. dos Crisântemos, Tv. das Hortênsias, Tv. das Palmas, Tv. das Camélias, Tv. das Gerberas, R. Guilherme Schultz Filho, R. Nossa Senhora Aparecida, Av. Universidade das Missóes, Av. Salgado Filho entre a Av. Jetúlio Vargas e a Av. Venâncio Aires, Av. Venâncio Aires entre a Av. Salgado filho), além do Campus da URI - Santo Ângelo e o Residencial Floripa, na busca por espécies com potencial para utilizar na ornamentação. As espécies nativas encontradas foram registradas através de fotografias para posterior análise de suas características e potenciais ornamentais.

\section{RESULTADOS}

Durante as saídas de campo foram registrados por fotografia 73 indivíduos, sendo identificadas 36 espécies nativas com potencial paisagístico, pertencentes a 13 famílias botânicas. As famílias botânicas encontradas foram: Asteraceae (8), Acanthaceae (1), Comelinaceae (2), Convolvulaceae (3), Iridaceae (3), Lythraceae (2), Malvaceae (1), 
Onagraceae (1), Oxalidaceae (3), Poaceae (7), Rubiaceae (1), Solanaceae (2) e Verbenaceae (2) (Figura 1; Tabela 1). Quanto às categorias por hábitos de vida foram encontradas plantas nativas distribuídas em quatro categorias: arbusto (3), subarbusto (7), herbáceo (23) e trepadeira (3) (Figura 2). Na Tabela 1 se encontra a descrição das características das plantas nativas com potencial paisagístico de Santo Ângelo-RS.

Figura 1- Diversidade de famílias botânicas encontradas com espécies vegetais nativas de potencial paisagístico em Santo Ângelo, RS (Autores, 2020).

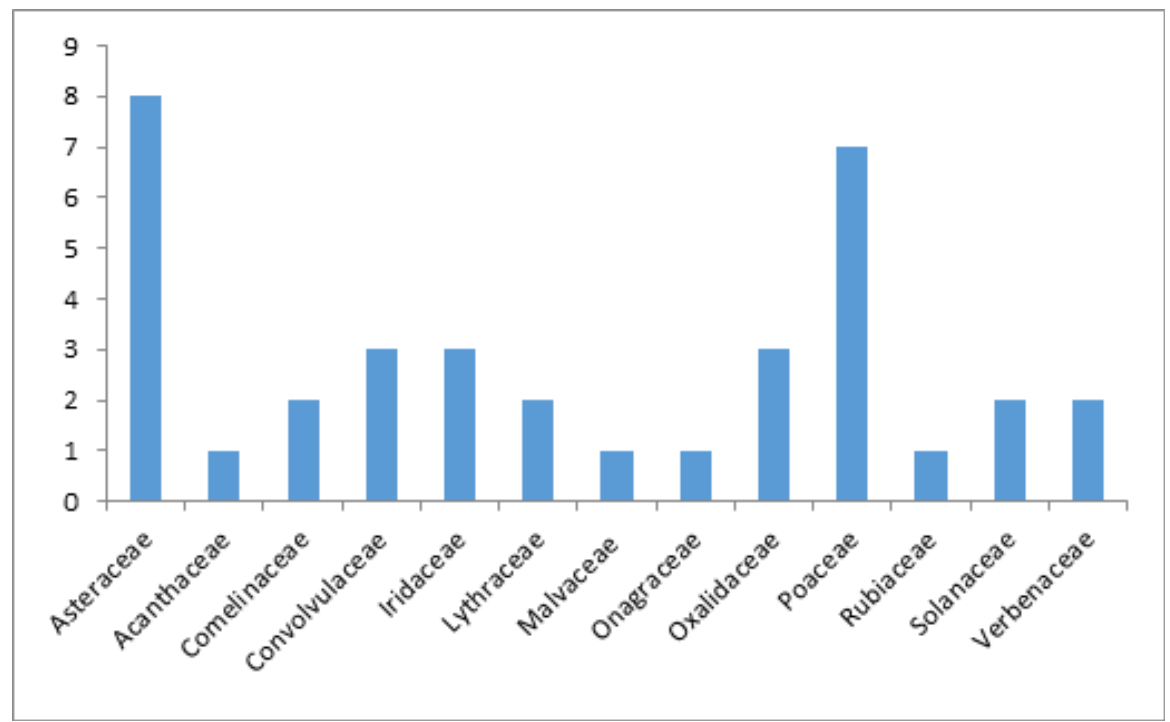

Legenda - Textura das folhas e das flores: opaca ou brilhosa, lisa ou rugosa e pilosa ou glabra, determinado visualmente. Cor das flores e folhas: definido visualmente. Indicativa de uso: locais apropriados onde a planta pode ser utilizada. Potencial paisagístico: características que mais se destacam da planta. --------------: esse sinal é empregado quando não foram encontradas informaçóes sobre a característica específica da planta.

Figura 2- Diversidade de hábitos encontrados em espécies vegetais nativas com potencial paisagístico em Santo Ângelo, RS (Autores, 2020).

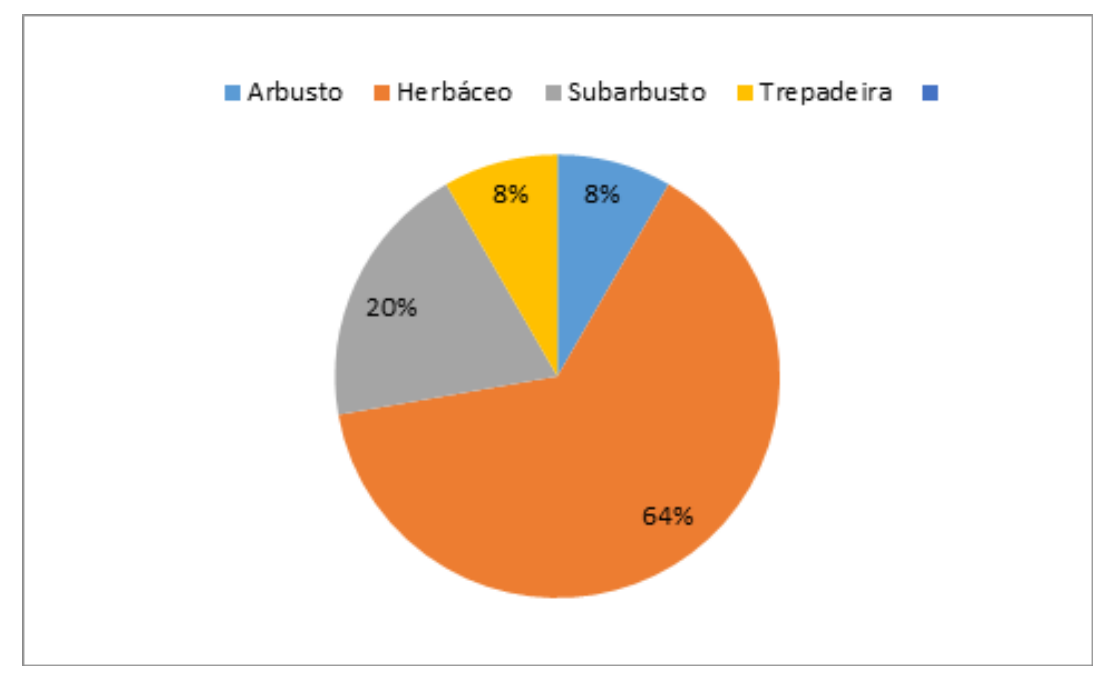


Tabela 1 - Descrição das características das plantas nativas com potencial paisagístico encontradas em Santo Ângelo, RS

\begin{tabular}{|c|c|c|c|c|c|c|c|c|}
\hline Família & Espécie & N. popular & Hábito & Textura & Cor & Floração & Indicativa de uso & Potencial paisagístico \\
\hline \multirow[t]{8}{*}{ Asteraceae } & $\begin{array}{l}\text { Aspilia } \\
\text { Montevidensis } \\
\text { (Spreng.) Kuntze }\end{array}$ & $\begin{array}{l}\text { Mal-me-quer e } \\
\text { margarida-do- } \\
\text { campo }\end{array}$ & Herbácea & $\begin{array}{l}\text { Folha: opaca, pilosa } \\
\text { e lisa. } \\
\text { Flor: Opaca, glabra } \\
\text { e lisa }\end{array}$ & $\begin{array}{l}\text { Flor: amarela } \\
\text { Folhas: verdes } \\
\text { de tom escuro }\end{array}$ & Ano todo & $\begin{array}{l}\text { Vasos de flor, jardins, } \\
\text { forração. Locais de } \\
\text { pleno sol. }\end{array}$ & $\begin{array}{l}\text { Grande quantidade de } \\
\text { flores vistosas e de cor } \\
\text { vibrante }\end{array}$ \\
\hline & $\begin{array}{l}\text { Chromolaena } \\
\text { laevigata } \\
\text { (Lam.) } \\
\text { R.M.King \& } \\
\text { H.Rob }\end{array}$ & $\begin{array}{l}\text { Cambará-falso e } \\
\text { mata-pasto. }\end{array}$ & Arbusto & $\begin{array}{l}\text { Folha: opaca, } \\
\text { glabra e lisa. } \\
\text { Flor: opaca, glabra } \\
\text { e lisa. }\end{array}$ & $\begin{array}{l}\text { Flor: branca } \\
\text { Folhas: verde } \\
\text { escuro. }\end{array}$ & Ano todo & $\begin{array}{l}\text { Jardins, arranjos florais. } \\
\text { Em locais de pleno sol. }\end{array}$ & $\begin{array}{l}\text { Com flores delicadas e } \\
\text { harmônicas. }\end{array}$ \\
\hline & $\begin{array}{l}\text { Campuloclinium } \\
\text { macrocephalum } \\
\text { (Less.) DC. }\end{array}$ & $\begin{array}{l}\text { Eupatório-roxo e } \\
\text { erva pom-pom. }\end{array}$ & Subarbusto. & $\begin{array}{l}\text { Folha: opaca, pilosa } \\
\text { e lisa. } \\
\text { Inflorescência: } \\
\text { opaca, glabra e lisa }\end{array}$ & $\begin{array}{l}\text { Inflorescência: } \\
\text { vinho e lilás } \\
\text { Folhas: verde } \\
\text { escuro. }\end{array}$ & $\begin{array}{l}\text { Dezembro } \\
\text { e junho }\end{array}$ & $\begin{array}{l}\text { Jardins e arranjos. Em } \\
\text { locais de pleno sol. }\end{array}$ & Cores vibrantes da flor. \\
\hline & $\begin{array}{l}\text { Chaptalia nutans } \\
\text { (L.) Polak. }\end{array}$ & $\begin{array}{l}\text { Língua-de-vaca, } \\
\text { costa-branca, } \\
\text { fumo-do-mato e } \\
\text { etc . }\end{array}$ & Herbácea & $\begin{array}{l}\text { Folha: opaca, } \\
\text { glabra e rugosa. } \\
\text { Inflorescência: } \\
\text { opaca, pilosa e lisa. }\end{array}$ & $\begin{array}{l}\text { Inflorescência: } \\
\text { branca } \\
\text { Folha: verde } \\
\text { escuro. }\end{array}$ & Setembro & $\begin{array}{l}\text { Pode-se utilizar em } \\
\text { jardins e vasos de flor, } \\
\text { em pleno sol e meia } \\
\text { sombra. }\end{array}$ & Possui folhas vistosas. \\
\hline & $\begin{array}{l}\text { Emilia fosbergii } \\
\text { Nicolson }\end{array}$ & $\begin{array}{l}\text { Algodão-de-preá, } \\
\text { serralha, } \\
\text { serralhinha e etc. }\end{array}$ & Herbácea & $\begin{array}{l}\text { Folha: opaca, } \\
\text { glabra e lisa. } \\
\text { Inflorescência: } \\
\text { opaca, pilosa e lisa. }\end{array}$ & $\begin{array}{l}\text { Flor: vermelho } \\
\text { coral } \\
\text { Folha: verde } \\
\text { escuro }\end{array}$ & $\begin{array}{l}\text { Fevereiro, } \\
\text { maio, } \\
\text { agosto e } \\
\text { outubro. }\end{array}$ & $\begin{array}{l}\text { Utilizar em jardins e } \\
\text { arranjos florais. }\end{array}$ & $\begin{array}{l}\text { Flores de cor vibrantes, } \\
\text { folhas vistosas. }\end{array}$ \\
\hline & $\begin{array}{l}\text { Solidago chilensis } \\
\text { Meyen }\end{array}$ & $\begin{array}{l}\text { Lanceta, arnica- } \\
\text { brasileira, }\end{array}$ & Subarbusto & $\begin{array}{l}\text { Inflorescência: } \\
\text { opaca, glabra e } \\
\text { rugosa } \\
\text { Folha: opaca, } \\
\text { glabra e lisa. }\end{array}$ & $\begin{array}{l}\text { Inflorescência: } \\
\text { amarela } \\
\text { Folha: verde }\end{array}$ & $\begin{array}{l}\text { Entre } \\
\text { maio e } \\
\text { junho }\end{array}$ & $\begin{array}{l}\text { Arranjos florais, } \\
\text { cultivo em canteiros } \\
\text { formando maciços. }\end{array}$ & Inflorescência vistosa. \\
\hline & $\begin{array}{l}\text { Sonchus oleraceus } \\
L \text {. }\end{array}$ & $\begin{array}{l}\text { Chicória-brava, } \\
\text { ciúmo, serralha e } \\
\text { etc. }\end{array}$ & Herbácea & $\begin{array}{l}\text { Flor: opaca, glabra } \\
\text { e lisa } \\
\text { Folha: opaca, } \\
\text { glabra e rugosa }\end{array}$ & $\begin{array}{l}\text { Flor: amarela } \\
\text { Folha: verde } \\
\text { escuro. }\end{array}$ & $\begin{array}{l}\text { Entre } \\
\text { janeiro e } \\
\text { agosto }\end{array}$ & $\begin{array}{l}\text { Utilizar em jardins, em } \\
\text { pleno sol. }\end{array}$ & $\begin{array}{l}\text { Possui flores delicadas } \\
\text { e vistosas. }\end{array}$ \\
\hline & $\begin{array}{l}\text { Tridax } \\
\text { procumbens } \mathrm{L} .\end{array}$ & Erva-de-touro & Herbácea & $\begin{array}{l}\text { Flor: opaca, glabra } \\
\text { e lisa } \\
\text { Folha: opaca, pilosa } \\
\text { e lisa. }\end{array}$ & $\begin{array}{l}\text { Flor: amarelo e } \\
\text { bege } \\
\text { Folha: verde } \\
\text { escuro }\end{array}$ & Ano todo & $\begin{array}{l}\text { Pode-se utilizar no } \\
\text { jardim e em canteiros e } \\
\text { para forração. }\end{array}$ & $\begin{array}{l}\text { Planta forrageira com } \\
\text { flores delicadas. }\end{array}$ \\
\hline Acanthaceae & $\begin{array}{l}\text { Stenandrium } \\
\text { dulce (Cav.) Nees }\end{array}$ & 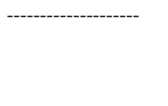 & Herbácea & $\begin{array}{l}\text { Flor: opaca, glabra } \\
\text { e lisa } \\
\text { Folha: brilhante, } \\
\text { pilosa e lisa }\end{array}$ & $\begin{array}{l}\text { Flor: Rosa } \\
\text { Folha: verde } \\
\text { escuro }\end{array}$ & $\begin{array}{l}\text { Entre } \\
\text { fevereiro e } \\
\text { março }\end{array}$ & $\begin{array}{l}\text { Pode-se utilizar em } \\
\text { jardins como forração e } \\
\text { como flor ornamental } \\
\text { de vasos. }\end{array}$ & $\begin{array}{l}\text { Flor de cor muito } \\
\text { vibrante e vistosa. }\end{array}$ \\
\hline \multirow[t]{2}{*}{ Comelinaceae } & $\begin{array}{l}\text { Commelina erecta } \\
\text { L. }\end{array}$ & $\begin{array}{l}\text { Flor-de-santa- } \\
\text { luzia, trapoeraba e } \\
\text { etc. }\end{array}$ & Herbácea & $\begin{array}{l}\text { Flor: brilhante, } \\
\text { glabra e rugosa } \\
\text { Folha: brilhosa, } \\
\text { glabra e lisa }\end{array}$ & $\begin{array}{l}\text { Flor: azul } \\
\text { Folha: verde } \\
\text { escuro. }\end{array}$ & Ano todo & $\begin{array}{l}\text { Forração em jardins e } \\
\text { para vasos formando } \\
\text { maciços. Prefere locais } \\
\text { mais úmidos. }\end{array}$ & Flor e folha vistosas \\
\hline & $\begin{array}{l}\text { Tripogandra } \\
\text { diurética (Mart.) } \\
\text { Handlos }\end{array}$ & $\begin{array}{l}\text { Trapoeraba-rósea, } \\
\text { ondas-do-mar e } \\
\text { etc. }\end{array}$ & Herbácea & $\begin{array}{l}\text { Flor: opaca, glabra } \\
\text { e lisa } \\
\text { Folha: brilhosa, } \\
\text { glabra e lisa. }\end{array}$ & $\begin{array}{l}\text { Flor: rosa claro } \\
\text { Folha: verde } \\
\text { escuro }\end{array}$ & $\begin{array}{l}\text { Entre } \\
\text { fevereiro e } \\
\text { abril. }\end{array}$ & $\begin{array}{l}\text { Forração de jardins, } \\
\text { vasos em ambientes de } \\
\text { meia sombra. }\end{array}$ & $\begin{array}{l}\text { Flor delicada e folhas } \\
\text { vistosas. }\end{array}$ \\
\hline \multirow[t]{3}{*}{ Convolvulaceae } & $\begin{array}{l}\text { Ipomoea triloba } \\
\text { L. }\end{array}$ & $\begin{array}{l}\text { Corda-de-viola, } \\
\text { campainha e etc. }\end{array}$ & Trepadeira & $\begin{array}{l}\text { Flor: opaca, glabra } \\
\text { e lisa } \\
\text { Folha: opaca, } \\
\text { glabra e rugosa }\end{array}$ & $\begin{array}{l}\text { Flor: rosa claro. } \\
\text { Folha: verde } \\
\text { escuro }\end{array}$ & $\begin{array}{l}\text { Entre } \\
\text { dezembro } \\
\text { a maio. }\end{array}$ & $\begin{array}{l}\text { Cobrir cercas, grades e } \\
\text { janelas. Em vasos e } \\
\text { jardineiras também. }\end{array}$ & $\begin{array}{l}\text { Flores e folhas muito } \\
\text { vistosas e estéticas. }\end{array}$ \\
\hline & $\begin{array}{l}\text { Ipomoea indica } \\
\text { (Burm. F.) }\end{array}$ & Corda-de-viola & Trepadeira & $\begin{array}{l}\text { Flor: opaca, glabra } \\
\text { e lisa. } \\
\text { Folha: opaca, } \\
\text { glabra e rugosa. }\end{array}$ & $\begin{array}{l}\text { Flor: roxa } \\
\text { Folha: verde } \\
\text { escuro. }\end{array}$ & $\begin{array}{l}\text { Janeiro a } \\
\text { outubro. }\end{array}$ & $\begin{array}{l}\text { Cobrir estruturas como } \\
\text { grades, cercas e também } \\
\text { vasos e jardineiras. }\end{array}$ & $\begin{array}{l}\text { Flor muito vistosa e de } \\
\text { cor vibrante. }\end{array}$ \\
\hline & $\begin{array}{l}\text { Ipomoea nil (L.) } \\
\text { Roth }\end{array}$ & $\begin{array}{l}\text { Corda-de-viola, } \\
\text { campainha-azul, } \\
\text { corriola e etc. }\end{array}$ & Trepadeira & $\begin{array}{l}\text { Flor: opaca, glabra } \\
\text { e lisa } \\
\text { Folha: opaca, } \\
\text { glabra e rugosa. }\end{array}$ & $\begin{array}{l}\text { Flor: azul a lilás } \\
\text { claro } \\
\text { Folha: verde } \\
\text { escuro. }\end{array}$ & $\begin{array}{l}\text { Março a } \\
\text { julho }\end{array}$ & $\begin{array}{l}\text { Cobrir estruturas, } \\
\text { grades e janelas. } \\
\text { Também em vasos e } \\
\text { jardineiras. }\end{array}$ & $\begin{array}{l}\text { Flor muito vistosa e } \\
\text { chamativa. Formato } \\
\text { diferenciado da folha. }\end{array}$ \\
\hline Iridaceae & $\begin{array}{l}\text { Herbertia lahue } \\
\text { (Molina) } \\
\text { Goldblatt }\end{array}$ & Bibi & Herbácea & $\begin{array}{l}\text { Flor: opaca, glabra } \\
\text { e lisa. } \\
\text { Folha: brilhosa, } \\
\text { glabra e lisa }\end{array}$ & $\begin{array}{l}\text { Flor: lilás } \\
\text { Folha: verde }\end{array}$ & $\begin{array}{l}\text { Setembro } \\
\text { a } \\
\text { novembro. }\end{array}$ & $\begin{array}{l}\text { Vasos de flor e jardins. } \\
\text { Em locais sombreados e } \\
\text { meia sombra }\end{array}$ & $\begin{array}{l}\text { Flor vistosa e } \\
\text { chamativa. }\end{array}$ \\
\hline
\end{tabular}




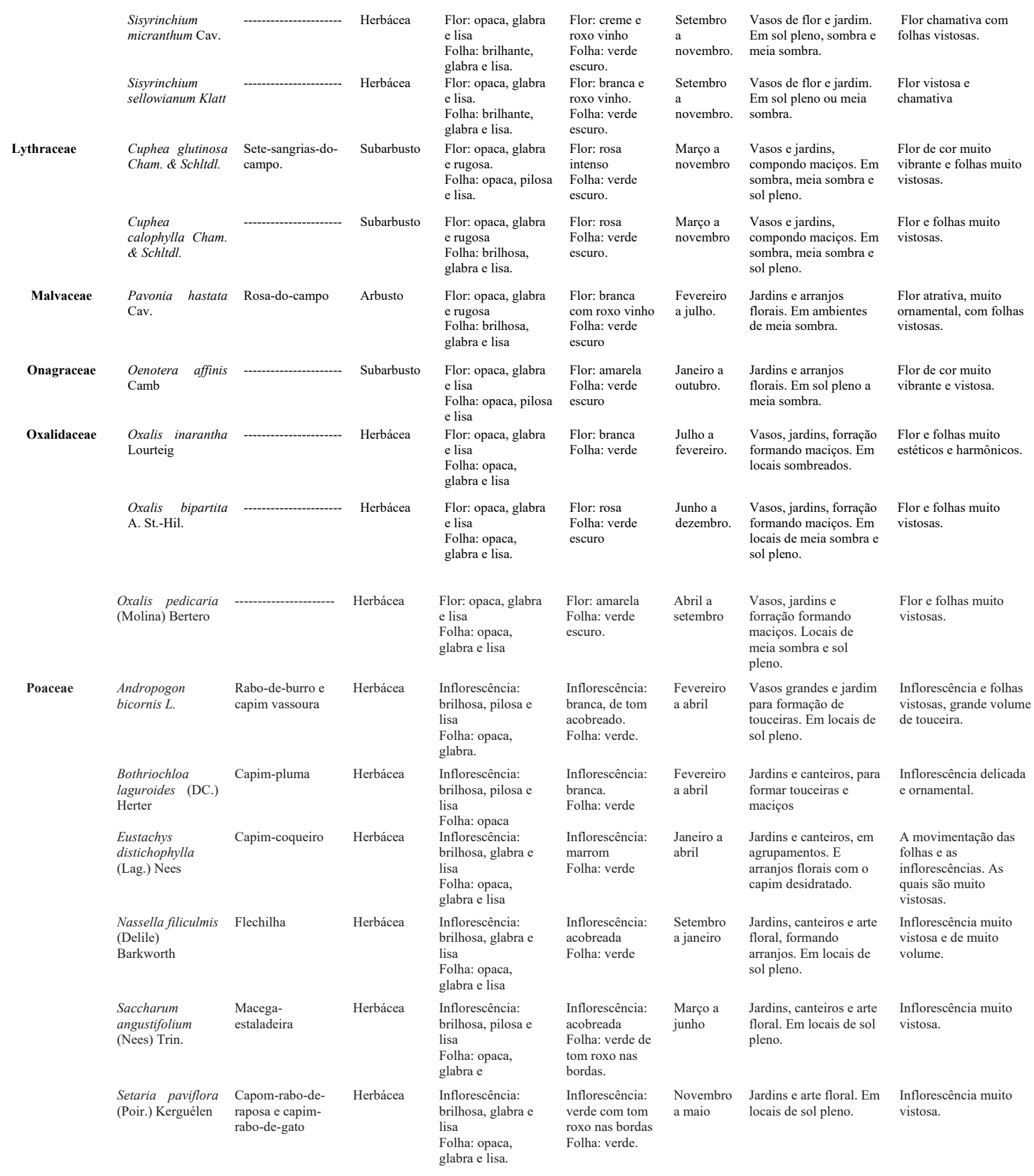




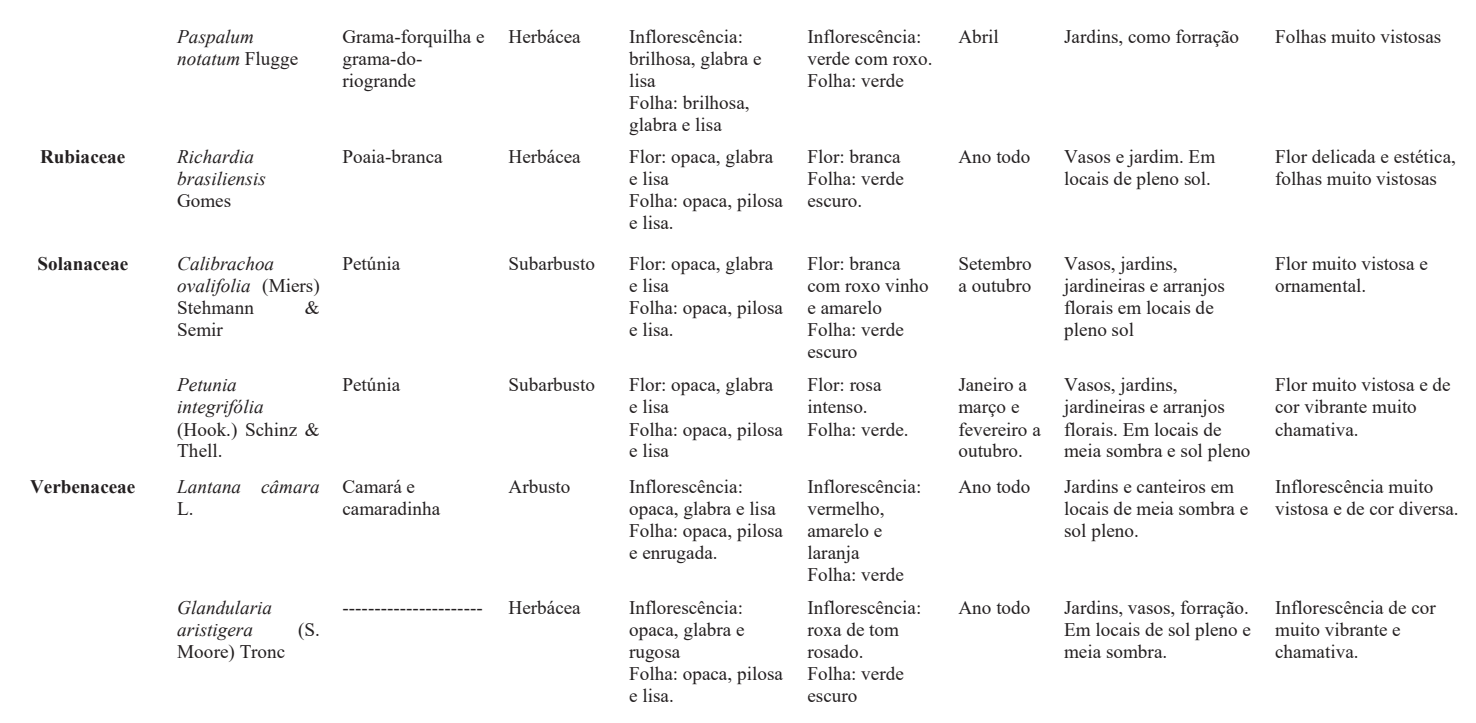

Legenda - Textura das folhas e das flores: opaca ou brilhosa, lisa ou rugosa e pilosa ou glabra, determinado visualmente. Cor das flores e folhas: definido visualmente. Indicativa de uso: locais apropriados onde a planta pode ser utilizada. Potencial paisagístico: características que mais se destacam da planta. ----------: esse sinal é empregado quando não foram encontradas informações sobre a característica específica da planta.

As espécies encontradas têm as mais diversas texturas e cores, podem ser utilizadas nos mais variados locais, desde cercas, canteiros, jardineiras, assim também como forração e formando maciços. Em locais de sol pleno, meia sombra e sombra, tem floração nos mais diversos períodos do ano, e o fator principal do potencial ornamental são as flores e folhas vistosas. As famílias com mais destaque foram a Asteraceae com 8 espécies e Poaceae com 7 espécies de potencial ornamental. $\mathrm{O}$ hábito de vida de maior predominância foi o herbáceo com 23 espécies.

\section{DISCUSSÃO}

No estudo de Moreira e Lopes ${ }^{14}$, realizado na Bacia do Rio Taquarembó RS, do total de espécies identificadas 166 táxons eram pertencentes a 33 famílias e possuíam potencial para serem utilizados como ornamentais, salienta-se que destas, apenas 51 espécies já são empregadas no paisagismo, principalmente as Cactaceae (15 espécies), bastante difundidas na Europa e América do Norte, seguido de Fabaceae (7 espécies) e Verbenaceae (4 espécies). Além dessas espécies foram identificadas plantas nativas pouco conhecidas que demonstram potencial ornamental, principalmente Fabaceae (13 espécies), Amaryllidaceae (12 espécies), Asteraceae (11 espécies), Iridaceae e Verbenaceae (10 espécies). Assim como Moreira e Lopes $^{17}$ forem encontrados no levantamento realizado as famílias Asteraceae, Commelinaceae, Convolvulaceae, Oxalidadaceae, Solanaceae, Poaceae, Iridaceae e verbenaceae, confirmando que as espécies identificadas aqui também possuem potencial paisagístico e de ornamentação.

Do mesmo modo que no estudo de Cavalcante et $\mathrm{al}^{15}$ foram encontradas as famílias Acanthaceae, Convolvulaceae, Malvaceae, Rubiaceae e Verbenaceae, que 
apresentaram grande diversidade de cores, texturas e formas. Cavalcate et $\mathrm{al}^{17}$ encontraram 43 espécies distribuídas em 22 famílias, destacando-se a família Fabaceae, representada por 13 espécies, que possuem características ornamentais e são indicadas para o uso no paisagismo, durante as saídas de campo observou-se no local as estruturas vegetais variando de flores e inflorescências, aspectos da textura, diversidade em cores, esta variabilidade de características possibilita o uso no paisagismo em suas diversas formas.

NotrabalhodeSousa ${ }^{16}$ foram mais relevantesasfamílias Asteraceae, Convolvulaceae, Rubiaceae, Poaceae e Malvaceae, e observou-se que a cor das folhas também varia do verde-claro ao verde escuro e a cor das flores apresentam tons quentes e frios. Na pesquisa de Sousa ${ }^{18}$ foram analisadas 44 espécies vegetais das quais 25 foram consideradas com potencial ornamental, pertencentes a 16 famílias, a maioria das espécies que analisou tem o porte trepador, podendo ser usadas em treliças, arcos, pérgulas, caramanchóes, alambrados e composiçáo com arbustos e árvores. A grande maioria das espécies possui folhas ou folíolos brilhantes lisos ou glabros e cores que variaram de verde-claro a verdeescuro, enquanto que as cores das flores de 8 espécies são frias e as espécies de cor da flor mais quente são mais vistosas.

Semelhante a Carrion ${ }^{17}$, foram encontradas as famílias: Asteraceae, Aacanthaceae, Convolvulaceae, Iridaceae, Malvaceae, Onagraceae, Oxalidaceae, Poaceae, Rubiaceae, Solanaceae e Verbenaceae, predominando o hábito herbáceo, seguido pelos subarbustos, e na mesma proporção para arbustos e trepadeiras. Contudo na pesquisa de Carrion ${ }^{19}$ foi encontrado 41 espécies, distribuídas em 20 famílias, sendo as 3 principais Fabaceae, Verbenaceae e Asteraceae, quanto a forma biológica das plantas predominaram as herbáceas, com 21 espécies, seguidas dos subarbustos, com sete espécies, dos arbustos, com cinco espécies e das trepadeiras, com seis espécies e também as arbóreas com duas espécies.

Uma das plantas que se destacou no levantamento realizado foi a Andropogon bicornis $L$, que possui potencial ornamental de acordo com o trabalho descrito por Stumpf et $\mathrm{al}^{18}$. As características especiais de coloração e o aroma das inflorescências, associadas aos demais atributos estéticos das hastes florais, mostram a originalidade da espécie. Não havendo no mercado flores de características semelhantes, mostrando assim a grande importância de encontrar essa espécie na cidade de Santo Ângelo, pois é uma alternativa na arte floral.

Mistura et $\mathrm{al}^{19}$ descrevem no livro algumas espécies que também foram encontradas neste levantamento como: Andropogon bicornis L., possuindo lindas inflorescências para arranjo floral ou em jardins como planta de fundo; Setaria paviflora (Poir.) Kerguélen, sendo indicado para uso na arte floral pelas suas inflorescências que são eretas, cilíndricas e compactas; Eustachys distichophylla (Lag.) Nees, se destacando quando utilizado em agrupamentos, devido ao movimento das suas inflorescências ao vento e também suas 
hastes florais podem ser utilizadas em arranjos secos e frescos; Nassella fliculmis (Delile) Barkworth, formando touceiras arredondadas, conferindo volume e leveza aos jardins e também possui aptidão para uso na arte floral.

No livro de Romano et al ${ }^{20}$ também são descritas algumas plantas em comum as encontradas nesse estudo como: Aspilia montevidensis (Spreng.) Kuntze, sendo rasteira e rústica, vistosa e com longo período de floração, tem indicativa para uso em jardins, como forraçáo em canteiros ou para o cultivo em vasos e floreiras a pleno sol; Campuloclinium macrocephalum (Less.) DC, características como comprimento e coloração das hastes, e por ter capítulos muito vistosos possibilitam a utilização na arte floral, pode ser cultivado em jardins em composição com outras espécies pela beleza do seu colorido; Solidago chilensis Meyen, por possuir inflorescências vistosas pode ser utilizado na arte floral e também em jardins onde é indicado para plantio em canteiros, para a formação de maciços; Calibrachoa ovalifolia (Miers) Stehmann \& Semir, apresenta rusticidade, com as flores vistosas e cores contrastantes, podendo ser cultivada como forração de canteiros ou em vasos e floreiras.

Algumas espécies nativas podem substituir as exóticas no paisagismo, como mostra Stumpf et al ${ }^{6}$, os arbustos e subarbustos podem ser ornamentados na implantaçáo de cercas-vivas e também para compor maciços e forraçóes, já as herbáceas podem ser utilizadas em locais de pleno sol, meia-sombra em canteiros e algumas espécies até mesmo em áreas alagadiças e, por fim as trepadeiras podem ser cultivadas como planta rasteira, compondo forrações em conjunto com outras espécies. Assim como sugerem Stumpf et $\mathrm{al}^{3}$, herbáceas, subarbustos, arbustos e trepadeiras, podem ser ornamentadas nos mais diferentes locais, trazendo harmonização aos espaços urbanos de forma mais sustentável, substituindo muitas exóticas.

\section{CONCLUSÃO}

O paisagismo é uma forma de aproximar a natureza da população das grandes cidades, trazendo um equilíbrio ecológico e, principalmente, deixando o clima local mais agradável. Muitas plantas que são utilizadas na ornamentação e paisagismo são exóticas e por vezes acabam tomando o lugar de espécies nativas, que também têm a sua importância.

Uma das maneiras para impedir que as espécies nativas se percam é utilizando as mesmas no paisagismo.

Este trabalho é o começo de uma iniciativa de tornar as plantas nativas de Santo Ângelo conhecidas. As espécies nativas têm as mais diversas cores, formas e texturas, e ainda podem ser utilizadas nos mais variados locais e ser atribuídas diversas funçóes, desde utilizadas como cerca-viva, canteiros, vasos de flor, forraçáo, formando maciços e entre outros, trazendo beleza a ambientes e mais qualidade de vida para a população. 
Santo Ângelo apresenta uma grande diversidade de espécies nativa, no entanto, é necessário trabalhar o conhecimento popular acerca delas, pois muitas ainda são consideradas como daninhas, sendo assim, tendo seu potencial subestimado.

É importante ressaltar ainda existem muitas plantas nativas com potencial para serem descritas, desde as herbáceas e até mesmo muitas arbóreas, que não fizeram parte deste trabalho.

\section{REFERÊNCIAS}

1- Gengo RC, Henkes JA. A utilizaçáo do paisagismo como ferramenta na preservação e melhoria ambiental em área urbana. Revista Gest. Sust. Amb. 2013 Mar: v. 1, n. 2; p. 55 - 8. Acesso em: 13 Mar. 2019. Disponível em: http://www.portaldeperiodicos. unisul.br/index.php/gestao_ambiental/article/view/1206

2- Pinheiro CR, Souza DD. A importância da arborizaçáo nas cidades e sua influência no microclima. Revista Gest. Sust. Amb. 2017 Set: v. 6, n. 1; p.67-82. Acesso em: 21 Jun. 2019. Disponível em: www.portaldeperiodicos.unisul.br/index.php/gestao_ ambiental/article/.../4179/3066

3- Sampaio AB, Schimidt IB. Espécies Exóticas Invasoras em Unidades de Conservação Federais do Brasil. Revista Instituto Chico Mendes de Conservação da Biodiversidade. Set 2013. Acesso em: 28 Mar. 2019. Disponível em: http://www.icmbio.gov.br/ revistaeletronica/index.php/BioBR/article/view/351

4- Costa VAM. Manejo de plantas invasoras na restauração em área de Mata Atlântica pós fogo [Dissertação de Mestrado]. Diamantina: Universidade Federal dos Vales do Jequitinhonha e Mucuri. Ciência Florestal, 2017. Acesso em: 20 Abr. 2019. Disponível em: http://acervo.ufvjm.edu.br/jspui/handle/1/1535

5- Lopes WGR, Matos KC, Mattaraia RA, Junior JHLL, Vieira GAR, Costa NAS. A presença de Roberto Burle Marx na cidade de Teresina, Piauí. Revista Cadernos de Urbanismo e Arquitetura. 2014: v. 21, n. 29; p.62-81. Acesso em: 6 Abr. 2019. Disponível em: http://periodicos.pucminas.br/index.php/Arquiteturaeurbanismo/ article/view/P.2316-1752.2014v21n29p62/10275

6- Stumpf ERT, Silva OS, Romagnoli ID, Fischer SZ, Mariot MP. Espécies nativas que podem substituir as exóticas no paisagismo. Revista Ornamental Horticulture. 2015 Jun: V. 21, No .2, 2015; p. 165-172. Acesso em: 15 Mai. 2019. Disponível em: https:// ornamentalhorticulture.emnuvens.com.br/rbho/article/viewFile/663/569

7- Lemos AC. Potencial ornamental da flora nativa e fenologia de quatro espécies de campo de altitude, Urupema, Santa Catarina, Brasil [Dissertaçáo de Mestrado]. Lages: Universidade do Estado de Santa Catarina. Centro de Ciências Agroveterinárias. 
Programa de Pós-Graduação em Produção Vegetal, 2016. Acesso em: 20 Abr. 2019. Disponível em: http://acervo.ufvjm.edu.br/jspui/handle/1/1535

8- Granemann FS, Santos KL, Granemann F, Steiner N. Caracterização de espécies vegetais nativas com potencial ornamental de ocorrência na região de Curitibanos, SC. Revista Agropecuária Catarinense. 2017 Abr: v.30, n.1; p.79-83. Acesso em: 10 Mar. 2019. Disponível em: http://publicacoes.epagri.sc.gov.br/index.php/RAC/article/ view/81/114

9- IBGE. Cidades. Rio Grande do Sul. Santo Ângelo. 2016. Acesso em: 14 mar 2019. Disponível em: http://cidades.ibge.gov.br/xtras/perfil.php? codmun=431750.

10- Hüller A, Rauber A, Wolski MS, Almeida NL, Wolski SRS. Estrutura fitossociológica da vegetação arbórea do Parque Natural Municipal de Santo Ângelo, Santo Ângelo, RS. Ciência Florestal, 2011 Dez: v. 21, n. 4; p. 629-639. Acesso em: 13 Mar. 2019. Disponível em: https://periodicos.ufsm.br/cienciaflorestal/article/ view/4508.

11- IRDeR - Instituto Regional de Desenvolvimento Rural - FIDENE/UNIJUÍ. Estação Pluviométrica, Augusto Pestana/RS. 2004.

12- Streck EV et al. Solos do Rio Grande do Sul. Porto Alegre, Universidade Federal do Rio Grande do Sul, 2002. 107 p.

13- Moreno JA. Clima do Rio Grande do Sul. Ci. Fl., v. 21, n. 4, out.-dez., Porto Alegre: Secretaria da Agricultura do Rio Grande do Sul, 1961. 73 p.

14- Moreira BP, Lopes SAOR. Espécies nativas com potencial ornamental ocorrentes na Bacia do Rio Taquarembó, RS. Revista Congrega. Out 2018. vol. 15, n. 15: p. 580591. Acesso em: 20 out. 2019. Disponível em: http://revista.urcamp.tche.br/index.php/ rcjpgp/article/view/2843

15- Cavalcante MZB, Dultra DFS, Silva HLC, Cotting JC, Silva SDP, Filho JAS. Potencial ornamental de espécies do Bioma Caatinga. Revista Com. Sci. 2017 Jan: v.8, n.1; p.43-58. Acesso em: 22 out. 2019. Disponível em: https://comunicatascientiae. com.br > comunicata > article > download

16- Sousa VF. Levantamento florístico e potencial ornamental de plantas da Restinga do Rio Grande do Norte, Brasil: subsídios para um paisagismo sustentável [Dissertação de Mestrado]. Macaíba: Universidade Federal do Rio Grande do Norte. Ciências Florestais. Unidade acadêmica especializada em ciências agrárias, 2016. Acesso em: 19 out. 2019. Disponível em: https://repositorio.ufrn.br/jspui/ bitstream/123456789/23235/1/LevantamentoFlor\%C3\%ADsticoPotencial_ Sousa_2016.pdf

17- Carrion AA. Potencial de plantas ornamentais nativas para o desenvolvimento rural no Município de Canguçu/RS [Dissertação de Mestrado]. Porto Alegre: Universidade 
Federal do Rio Grande do Sul. Faculdade de Ciências econômicas. Programa de Pós Graduação em desenvolvimento rural, 2013. Acesso em: 27 out. 2019. Disponível em: https://lume.ufrgs.br/handle/10183/87377

18- Stumpf ERT, Barbieri RL, Fischer SZ, Heiden G, Neitzke RS. Uso ornamental de Andropogon bicornis L. (Poaceae). Revista Ceres. Mar/Abr 2009. Acesso em: 05 nov. 2019. Disponível em: http://www.ceres.ufv.br/ojs/index.php/ceres/article/ view/3426/1305

19- Mistura CC, Stumpf ERT, Heiden G, Sallés JM, Marchi MM, Barbieri RL. Cores e formas do Bioma Pampa: gramíneas ornamentais nativas. 1a edição. Pelotas RS: Editora Embrapa Clima Temperado, 2015.

20- Romano CM, Stumpf ERT, Heiden G, Iganci JRV, Corrêa LB, Barbieri RL, Perleberg TD. Cores e Formas do Bioma Pampa: plantas ornamentais nativas. $1^{\mathrm{a}} \mathrm{ed}$. Pelotas, RS: Editora Embrapa Clima Temperado, 2009.

Autor Correspondente: Ricardo Dreilich Prestes E-mail: ricardodreilich@gmail.com

Recebido em: 2020-11-30

Aprovado: 2020-12-31 